\title{
Immunohistochemical detection of early-stage carcinogenesis of oral leuko- plakia by increased DNA-instability and various malignancy markers
}

\author{
M. Iwasa, Y. Imamura, S. Noriki, Y. Nishi, H. Kato, and M. Fukuda \\ Department of Pathology, Fukui Medical University, Matsuoka, Yoshida-Gun, 910-1193, Fukui, Japan
}

Accepted: 2/3/01

Key words: human oral leukoplakia, DNA-instability, AgNORs, PCNA, p53, DFF45

\section{SUMMARY}

The degree of DNA instability as determined by immunohistochemical staining with anti-singlestranded DNA antibody after acid hydrolysis (the DNA instability test) was used as a marker of malignancy. The test was applied to tissues of oral leukoplakia assessed histopathologically as hyperplasia (38 cases), mild (12 cases), moderate (11 cases) and severe (8 cases) dysplasia, and invasive squamous cell carcinoma (SCC, 20 cases). Tissues were subjected to immunohistochemical staining for proliferating cell nuclear antigen (PCNA), p53, DNA-fragmentation factor 45 (DFF45), analysis of various AgNORs parameters, and triple immunostaining for vascular endothelial growth factor (VEGF), CD34, and PCNA. The DNA instability test was positive in $20(100 \%)$ SCC cases, $8(100 \%)$ severe dysplasia cases, $8(72.7 \%)$ moderate dysplasia cases, 6 (50.0\%) mild dysplasia cases, and $9(23.7 \%)$ hyperplasia cases, indicating malignancy. The proportion of lesions positive for PCNA, p53, DFF45, and values of AgNORs parameters steadily increased from hyperplasia to mild, moderate and severe dysplasia, and SCC, especially in those showing positive DNA instability test, indicative of malignancy. Based on these results, $44.9 \%$ of leukoplakia were malignant tissues, namely carcinoma in situ. The proportion of
PCNA-positive vascular endothelial cells in the vicinity of VEGF-positive epithelial lesion was significantly higher than that of negative DNA instability lesions, as revealed by immunohistochemical triple staining for VEGF, CD34, and PCNA. Our results suggest that increased DNA instability, enhanced proliferative activity, p53 mutation, and induction of DFF45 and VEGF may allow cancer cell proliferation, enhance their survival by escaping apoptosis, and provide abundant nutrients during early-stage carcinogenesis of oral leukoplakia.

\section{INTRODUCTION}

Oral leukoplakia is regarded as a precancerous or potentially malignant lesion (Kramer et al., 1978), and is defined as "a predominantly white lesion of the oral mucosa that cannot be characterized as any other definable lesion" (Axéll et al., 1996). Histopathological grade of dysplasia is the most important indicator of the malignant potential of leukoplakia (Burkhardt, 1985). Dysplasia is characterised by 12 types of general disturbances in the epithelium (Kramer et al., 1978). The diagnosis of epithelial dysplasia, however, requires a considerable experience (Pindborg et al., 1985), and interobserver agreement rates are generally poor, rang- 
ing between $49 \%$ and $69 \%$ (Karabulut et al., 1995). Several groups have used the 12-histopathological diagnostic criteria of WHO to diagnose mild dysplasia as the presence of two of these features, moderate dysplasia by 2 to 4 features, and severe dysplasia by the presence of $\geq 5$ diagnostic features (Ramaesh et al., 1998). However, others have used conventional histopathological characterisation as dysplasia of mild (abnormality less than one-third of epithelial thickness), moderate (approximately two-thirds involvement), and severe (full-thickness abnormality) (Bouquot and Gnepp, 1991; Tsuzuki et al., 1994; Thomson et al., 1999).

The frequency of oral carcinoma in patients with oral leukoplakia ranges from $2.4 \%$ to $70.3 \%$ during a 6-20 year observation period (Einhorn and Wersäll., 1967; Silverman et al., 1984; Hansen et al., 1985; Silverman and Gorsky, 1997; Schepman et al., 1998; Lee et al., 2000). Furthermore, Lee et al. (2000) reported that the cancer risk of oral leukoplakia with moderate to severe dysplasia was 2.3 times higher than that with hyperplasia or mild dysplasia. However, malignancy could also develop in non-dysplastic lesions such as hyperplasia (Silverman et al., 1984; Hansen et al., 1985; Schepman et al., 1998; Murti et al., 1998).

As described above, the morphological criteria used for the diagnosis of malignancy are quite ambiguous and controversial, making the diagnosis of oral leukoplakia in clinical specimens often difficult. In order to enhance accurate diagnosis, many histochemical and biochemical methods have been applied to the dysplastic lesions in search for reliable markers of malignancy. For example, cytokeratin (Vaidya et al., 1998; Ibrahim et al., 1998), argyrophilic nucleolar organiser region staining (AgNORs) (Warnakulasuriya and Johnson, 1993; Chattopadhyay et al., 1994; Kobayashi et al., 1995), proliferating cell nuclear antigen (PCNA) (Tsuji et al., 1992; Nishioka et al., 1993; Kobayashi et al., 1995), p53 (Nishioka et al., 1993; Girod et al., 1994; Tsuji et al., 1995; Murti et al., 1998; Ries et al., 1998), Bcl-2 (Ravi et al., 1996), Fas (Muraki et al., 1997), integrin (Garzino et al., 1998; Hakkinen et al., 1999), vascular endothelial growth factor (VEGF) (Denhart et al., 1997; Maeda et al., 1998), cell and nuclear diameters (Ramaesh et al., 1998), and kinetic parameters of cell proliferation (Thomson et al., 1999) have been used for this purpose. Recently, Lee et al. (2000) demonstrated that a com- bined biomarker score of chromosomal polysomy, p53 positivity and loss of heterozygosity was the strongest predictor for cancer development in oral leukoplakia.

The above diagnostic tools demonstrate the presence of abnormal gene expression and protein synthesis, disturbed cytodifferentiation, stimulated cell proliferation activity, and DNA abnormalities during the course of progression of overt malignancy in oral leukoplakia. However, these could not be used as specific markers for the diagnosis of malignancy. In this regard, Fukuda et al. (1986, 1993) found that nuclear DNA of cancerous cells was less stable than that of comparable benign tumour cells and normal cells, irrespective of epithelial or mesenchymal origin. They also developed the method of differential fluorescent or immunohistochemical staining of cancerous cells after denaturation of nuclear DNA by acid hydrolysis. By using this method (the DNA instability test), cancerous clones could be identified during early stages of carcinogenesis in so-called borderline or precancerous lesions such as colorectal adenoma (Nitta et al., 1993), gastric adenoma (Otaki et al., 1994), otorhinolaryngeal borderline lesions (Tsuzuki et al., 1994), bone giant cell tumours (Azuchi et al., 1998), and uterine cervical dysplasia (Khaled et al., 2000).

In the present study, we used the DNA instability test as a marker of malignancy to identify cancer clones in early-stage leukoplakia. Cancer clones were recognised by increased DNA instability in hyperplastic and dysplastic leukoplakia and exhibited significantly higher values of PCNA labelling, abnormal AgNORs parameters, and immunoreactivity for p53, DNA fragmentation factor 45 (DFF45), and VEGF, compared with negative lesions.

\section{MATERIALS AND METHODS}

Immunohistochemical staining with polyclonal anti-single-stranded DNA antibody to demonstrate DNA-instability (DNA-instability test)

\section{(a) Tissue samples}

Paraffin-embedded sections (4 $\mu \mathrm{m}$ thick) were prepared from biopsies or surgically resected specimens of human oral normal mucosa (7 cas- 
es), non-dysplastic hyperplasia (38 cases), dysplasia (31 cases), and squamous cell carcinoma (20 cases), after fixation with $10 \%$ buffered formalin for $24 \mathrm{hr}$ at room temperature. Clinical diagnosis of leukoplakia was made according to WHO criteria (Kramer et al., 1978). Histopathological classification of dysplasia was performed using conventional criteria described above; mild dysplasia (12 cases), moderate dysplasia (11 cases), and severe dysplasia (8 cases).Tissue sections were deparaffinized with xylene and replaced by ethanol.

\section{(b) Preblocking}

After washing in water, intrinsic peroxidase was blocked with $0.3 \% \quad \mathrm{H}_{2} \mathrm{O}_{2}$ solution dissolved in absolute methanol at $20^{\circ} \mathrm{C}$ for $15 \mathrm{~min}$ and rinsed with PBS ( $\mathrm{pH} 7.4)$. Sections were mounted with 2\% skim-milk (Yukijirushi, Sapporo, Japan) dissolved in PBS (pH 7.4) at $37^{\circ} \mathrm{C}$ for 20 min to block the background adsorption of antiserum. Tissue sections were reacted with the blocking solution [Histofine PO(R), Nichirei, Tokyo, Japan].

\section{(c) Immunohistochemical staining of single-strand- ed DNA}

In the next step, sections were washed in water, and treated with $2 \mathrm{~N} \mathrm{HCl}$ at $30^{\circ} \mathrm{C}$ for $20 \mathrm{~min}$ for acid hydrolysis followed by re-washing in water. They were reacted with a polyclonal antibody to cytidine (Biogenesis, UK, 1:1,500 dilution) at $4^{\circ} \mathrm{C}$ overnight and rinsed with $\mathrm{PBS}$ at $(\mathrm{pH}$ 7.4). Sections were reacted with biotinylated goat anti-rabbit IgG [Histofine PO(R), Nichirei] at $37^{\circ} \mathrm{C}$ for 40 min and rinsed with PBS ( $\mathrm{pH} 7.4)$, followed by reaction with the avidin-biotin peroxidase complex (Histofine, Nichirei) at $37^{\circ} \mathrm{C}$ for $30 \mathrm{~min}$, and further rinsed with $\mathrm{PBS}(\mathrm{pH} 7.4)$.

\section{(d) Co-DAB reaction}

In order to visualize the peroxidase colour reaction, sections were incubated with DAB (3,3'diaminobenzidine tetrahydrochloride) cobalt solution [DAB, Dojin, Kumamoto, Japan, 5 mg dissolved in $100 \mathrm{ml}$ of $0.05 \mathrm{M}$ Tris- $\mathrm{HCl}$ buffer $(\mathrm{pH}$ 7.4), mixed with $2 \mathrm{ml}$ of $1 \% \mathrm{CoCl}_{2}$ and $10 \mu \mathrm{l}$ of $30 \% \mathrm{H}_{2} \mathrm{O}_{2}$ solution] at $20^{\circ} \mathrm{C}$ for $10 \mathrm{~min}$ and washed in water. Nuclear counterstaining was performed with Kernechtrot (Kernechtrot, Chroma, Stuttgart, Germany, $100 \mathrm{mg}$ and aluminium sulphate $5 \mathrm{~g}$ dissolved in $100 \mathrm{ml}$ distilled water). (e) Evaluation of DNA-instability test

Sections containing positively stained cells were regarded as positive for malignancy.

\section{Immunohistochemical staining of PCNA, p53 and DNA-fragmentation factor}

Serial $4 \mu \mathrm{m}$ sections were prepared from the same specimens used for the DNA instability test as described above. They were irradiated in a poly-propylene slide holder with a cap filled with $10 \mathrm{mM}$ Na-citrate buffer ( $\mathrm{pH}$ 6.0), over a period of $10 \mathrm{~min}$, using an autoclave (Hirayama, $1.5 \mathrm{~kW}$, Tokyo). After washing with water, intrinsic peroxidase activity was blocked with $0.3 \% \mathrm{H}_{2} \mathrm{O}_{2}$ solution dissolved in absolute methanol at $20^{\circ} \mathrm{C}$ for 15 min and rinsed with PBS ( $\mathrm{pH} 7.4)$. Sections were then mounted with $2 \%$ skim-milk (Yukijirushi) dissolved in PBS ( $\mathrm{pH} 7.4$ ) at $37^{\circ} \mathrm{C}$ for $30 \mathrm{~min}$ to block the background adsorption of antiserum, then further reacted with the blocking solution [Histofine $\mathrm{PO}(\mathrm{M})$, Nichirei] at $20^{\circ} \mathrm{C}$ for $5 \mathrm{~min}$. This was followed by reactions with the following primary antibodies at $4^{\circ} \mathrm{C}$ overnight: monoclonal anti-PCNA antiserum [PC-10, NC-012, Novocastra, Newcastle, UK, $50 \mu$ dissolved in $2.5 \mathrm{ml}$ PBS (pH 7.4), mixed with $0.02 \%$ Triton $X-100]$, or monoclonal anti-p53 antibody (Ab-6,Calbiochem, USA, 1:40 dilution). Sections were then washed with PBS ( $\mathrm{pH} 7.4$ ), further reacted with biotinylated rabbit anti-mouse IgG [Histofine PO(M), Nichirei] at $37^{\circ} \mathrm{C}$ for $30 \mathrm{~min}$, followed by rinsing with PBS ( $\mathrm{pH} 7.4$ ). They were allowed to react with the avidin-biotin peroxidase complex at $37^{\circ} \mathrm{C}$ for $30 \mathrm{~min}$, and rinsed with PBS (pH 7.4). In order to visualize the peroxidase colour reaction, the sections were incubated with DAB cobalt solution at $20^{\circ} \mathrm{C}$ for $10 \mathrm{~min}$ and washed in water. Nuclear counterstaining was carried out with Kernechtrot. Immunohistochemical staining for DNA-fragmentation factor was performed in a similar fashion except for using polyclonal anti-DNA- fragmentation factor antibody (NCL-DFFp, Novocastra, Newcastle, UK, 1:200 dilution) as the primary antiserum. Biotinylated goat anti-rabbit IgG was selected as the secondary antiserum with the blocking solution for rabbit [Histofine PO(R), Nichirei].

The extent of PCNA-positive staining was evaluated semi-quantitatively by determining the number of positively stained nuclei in at least 500 epithelial cells in all layers per specimen using an 
Olympus microscope $(\times 40$ objective and $\times 10$ eye piece). As for p53 and DNA-fragmentation factor staining, cases with $>5 \%$ positively stained cells (counted using the same method described above for PCNA-positive cases) were considered positive.

\section{Immunohistochemical triple staining for VEGF, CD34 and PCNA}

Specimens obtained from the same tissues used for the other immunohistochemical staining methods were used. Deparaffinized and alcoholreplaced specimens were washed with distilled water. To activate various antigens, sections were irradiated in a manner similar to that described above except for using microwaving (500 W, ER245, Toshiba, Tokyo), three times, each for $5 \mathrm{~min}$, instead of autoclaving. Immunohistochemical staining for PCNA was carried out first using the method described above, except for omitting the process of skim-milk treatment. After washing with water, sections were reacted with monoclonal anti-endothelial cell marker (CD34) antibody (NCL-END, Novocastra, 1:25 dilution with PBS, $\mathrm{pH} 7.4$ ) at $4^{\circ} \mathrm{C}$ overnight. They were then washed with PBS ( $\mathrm{pH} 7.4)$, and further reacted with biotinylated rabbit anti-mouse IgG [Histofine $\mathrm{PO}(\mathrm{M})$, Nichirei] at $37^{\circ} \mathrm{C}$ for $30 \mathrm{~min}$, followed by rinsing with $\mathrm{PBS}$ ( $\mathrm{pH}$ 7.4). They were allowed to react with the avidin-biotin peroxidase complex (Histofine, Nichirei) at $37^{\circ} \mathrm{C}$ for $30 \mathrm{~min}$, rinsed with PBS (pH 7.4), and then incubated with DAB solution. Sections were washed with water and reacted overnight with monoclonal anti-VEGF antibody (C-1, Santa Cruz Biotechnology, CA, 1:150 dilution with $\mathrm{PBS}, \mathrm{pH} 7.4)$ at $4^{\circ} \mathrm{C}$. They were washed with PBS ( $\mathrm{pH} 7.4$ ) and further reacted with biotinylated rabbit anti-mouse $\mathrm{IgG}$ [Histofine $\mathrm{PO}(\mathrm{M})$, Nichirei] at $37^{\circ} \mathrm{C}$ for $30 \mathrm{~min}$, followed by rinsing with PBS ( $\mathrm{pH} 7.4)$. Sections were further reacted with biotinylated rabbit antimouse IgG [Histofine SAB-AP(M), Nichirei] at

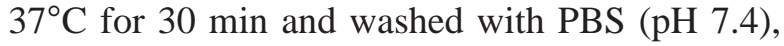
followed by reaction with alkaline phosphataselabelled streptoavidin [Histofine SAB-AP(M), Nichirei] at $37^{\circ} \mathrm{C}$ for $1 \mathrm{hr}$ and washed with PBS (pH 7.4). In order to visualize the colour reaction of alkaline phosphatase, specimens were dipped in the reaction mixture for $30 \mathrm{~min}$ at room temperature. The reaction mixture was prepared by adding $0.1 \mathrm{ml}$ of the substrate solution [10 mg naphthol-
AS-BI-phosphate (Sigma, Steinheim, Germany) dissolved in $0.1 \mathrm{ml} \mathrm{N}, \mathrm{N}$-dimetyl formamide, Nacalai, Kyoto] to a solution composed of $0.1 \mathrm{ml}$ of 4\% fuchsin solution [4.0 $\mathrm{g}$ fuchsin basic (Nacalai, Kyoto, Japan) dissolved in $100 \mathrm{ml} \mathrm{2N}$ $\mathrm{HCl}$ ] and $0.1 \mathrm{ml}$ of $4 \%$ sodium nitrite solution [4.0 g sodium nitrite (Nacalai, Kyoto) dissolved in 100 $\mathrm{ml}$ distilled water] in $0.2 \mathrm{M}$ Tris $\mathrm{HCl}$ buffer $(\mathrm{pH}$ 8.2) (Trizma hydrochloride, Sigma, $6.06 \mathrm{~g}$ dissolved in $1,000 \mathrm{ml}$ distilled water).

PCNA-positivity was evaluated by determining the number of positively stained nuclei in at least 50 endothelial cells per one stromal area adjacent to VEGF-positive epithelial cell region. As for VEGF, cases with areas of positively stained cells were regarded as positive.

\section{AgNORs}

Specimens obtained from the same tissues used in other staining procedures were used. Deparaffinized and alcohol replaced specimens were washed with de-ionised and distilled water, and coated with $2 \mathrm{~g} / \mathrm{dl}$ gelatine dissolved in $1 \mathrm{~g} / \mathrm{dl}$ formic acid solution mixed with twice the volume of $50 \mathrm{~g} / \mathrm{dl}$ silver nitrate, and allowed to react at $20^{\circ} \mathrm{C}$ for $15 \mathrm{~min}$ under a safety light (No. LA, Kodak, NY). Specimens were then fixed with Fuji-fix solution (Fujifix, Fuji Photo Film, Tokyo, $445 \mathrm{~g}$ dissolved in 2.01 of de-ionised and distilled water) for $1 \mathrm{~min}$ at room temperature and thoroughly washed in de-ionised and distilled water. No nuclear counterstaining was performed.

\section{Quantitative analysis of AgNORs}

The colour image analysis software, MacScope ver 2.56 (Mitani, Fukui, Japan) was used for this analysis. The image of an optical field of a specimen stained by the AgNORs technique was collected with an objective lens (x100) and projected on a cathode ray tube (CRT). The total number of AgNORs in one optical field or in each nucleus was counted manually. The total area $\left(\mu \mathrm{m}^{2}\right)$ of all AgNORs per optical field or nucleus was computed by the software, as well as the mean AgNORs area \pm SD per optical field or per nucleus. Three to five optical fields, i.e., roughly about 100 cells, were examined in each specimen. The mean value of the maximum shape irregularity of AgNORs expressed as the degree of deviation from a regular circle, was computed for the most irregularly 
shaped AgNORs in 10 nuclei in each specimen, by the same examiner, on a photograph printed from the CRT image with a final magnification of $\times 1,000$.

\section{Statistical Analysis}

PCNA-index and AgNORs parameters are presented as mean \pm standard deviation. Data were analysed using Student's $t$-test. Staining for p53, DNA fragmentation factor, VEGF and anti-singlestranded DNA antibody was compared in different lesions by the chi-square test and Fisher's exact test. A $p$ value $<0.05$ denoted the presence of a significant statistical difference.

\section{RESULTS}

The results of immunohistochemical staining of DNA-instability, PCNA, p53, and DFF45 and AgNORs parameters are summarized in Table I. The data for these parameters in relation to the results of the DNA-instability test are also listed in Table II. The PCNA-index of capillary endothelial cells positive for CD34 in the neighbourhood of VEGF-positive and negative epithelial lesions determined by immunohistochemical triple staining are also summarized in Tables I and II.

\section{DNA-instability test}

After hydrolysis with $2 \mathrm{~N} \mathrm{HCl}$ at $30^{\circ} \mathrm{C}$ for $20 \mathrm{~min}$, all cancer cells stained positive with anti-singlestranded DNA antibody, indicating increased DNA-instability (positive DNA-instability test, Fig. 1e). On the other hand, normal epithelial cells, stromal fibroblasts, vascular endothelial cells and inflammatory cells in the same slide were negative. In general, almost all cells of dysplastic regions in all cases with severe dysplasia stained positive, indicating that the increased DNA-instability is just comparable to that of cancer cells (Fig. 1d). In 9 $(23.7 \%)$ cases with hyperplasia without recognizable dysplastic changes, cells in several basal-side layers were diffusely and sporadically stained, with sporadic positively stained cells in the upper layers (Fig. 1a). In 6 (50.0\%) cases with mild dysplasia, all cells in dysplastic regions and several upper layer cells without marked dysplasia were diffusely positive, and cells in the top layers and dysplastic areas were also sometimes sporadically stained positively (Fig. 1b). In 8 (72.7\%) cases with mod- erate dysplasia, cells in dysplastic regions occupying basal-side layers forming more than two-thirds of the entire mucosal thickness were diffusely stained, and many sporadically stained cells were noted in the upper layers. In the remaining cases with a negative DNA-instability, no positively stained cells were found. Thus, the extent of immunostaining by anti-single-stranded DNA antiserum increased in hyperplastic, dysplastic, and invasive cancer (SCC) lesions. Furthermore, there was a significant difference in staining between these tissues and between different dysplastic lesions $(p<0.05)$, but not between hyperplasia and mild dysplasia.

\section{PCNA immunohistochemistry}

In normal squamous and hyperplastic squamous epithelium with a negative DNA-instability test, PCNA-labelled cells were well localized in the basal layer showing preserved polarity of cytodifferentiation. The PCNA index was significantly higher in moderate dysplasia, severe dysplasia and in SCC than those in normal and hyperplastic cases (Fig. 1f-j, Table I). Moreover, the PCNA index of DNA-instability-test-positive total dysplastic lesions was significantly higher than that of DNAinstability-test-negative cases (Table II). In all hyperplasia, dysplasia and SCC lesions with positive DNA-instability test, the distribution of PCNA-positive cells coincided well with that of DNA-instability-test-positive cells, with spreading throughout the entire mucosal thickness or more than one-third of the mucosal layer, indicating disturbed cytodifferentiation. In all cancer cases, the distribution of PCNA-positive cells was diffuse and random, indicating marked disturbance of polarity. The PCNA indices of severe dysplasia and SCC were significantly higher than that of mild dysplasia (Table I).

\section{P53 immunohistochemistry}

Normal squamous epithelia were negative for p53. On the other hand, 6/38 (15.8\%) cases of hyperplasia were positive for $\mathrm{p} 53$ immunostaining (Fig. 1k). As shown in Table I, the percentages of p53 positive cells in mild, moderate, and severe dysplasia, all dysplastic lesions, and SCC were 33.3, 45.5, 50.0, 41.9 and 65.0, respectively. All these values, with the exception of that of mild dysplasia, were significantly higher than that of 
hyperplasia. There was no difference in the proportion of p53-positive cases with mild, moderate and severe dysplasia; however, the proportion of cases with mild dysplasia was significantly different from that of SCC. On the other hand, among the 9 DNA-instability test positive hyperplastic lesions, 4 (44.4\%) cases were also positive for $\mathrm{p} 53$, whereas in the 29 DNA-instability-test-negative group, only $2(6.9 \%)$ cases expressed p53; the difference between the two types was significant (Table II). In mild dysplasia, the proportions of p53-positive cells in DNA-instability-testpositive and a negative cases were 66.7 and $0 \%$, respectively. The proportion of p53positive cells in moderate dysplasia tended to be higher in DNA-instability-test-positive cases $(50.0 \%)$ than negative cases $(33.3 \%)$, albeit statistically insignificant. The proportions of p53-positive cells in the entire group of dysplastic lesions with a positive DNA-instability test $(54.6 \%$, including mild, moderate and severe dysplasia) and in the entire group of lesions with leukoplakia $(51.6 \%$, including hyperplasia and dysplasia cases) were significantly higher than those with a negative DNAinstability test $(11.1 \%, 7.9 \%$, respectively, Table II).

A single case of moderate dysplasia with a negative DNA-instability test was positive for $\mathrm{p} 53$, but $\mathrm{p} 53$-positive cells were present sporadically and limited to the basal 


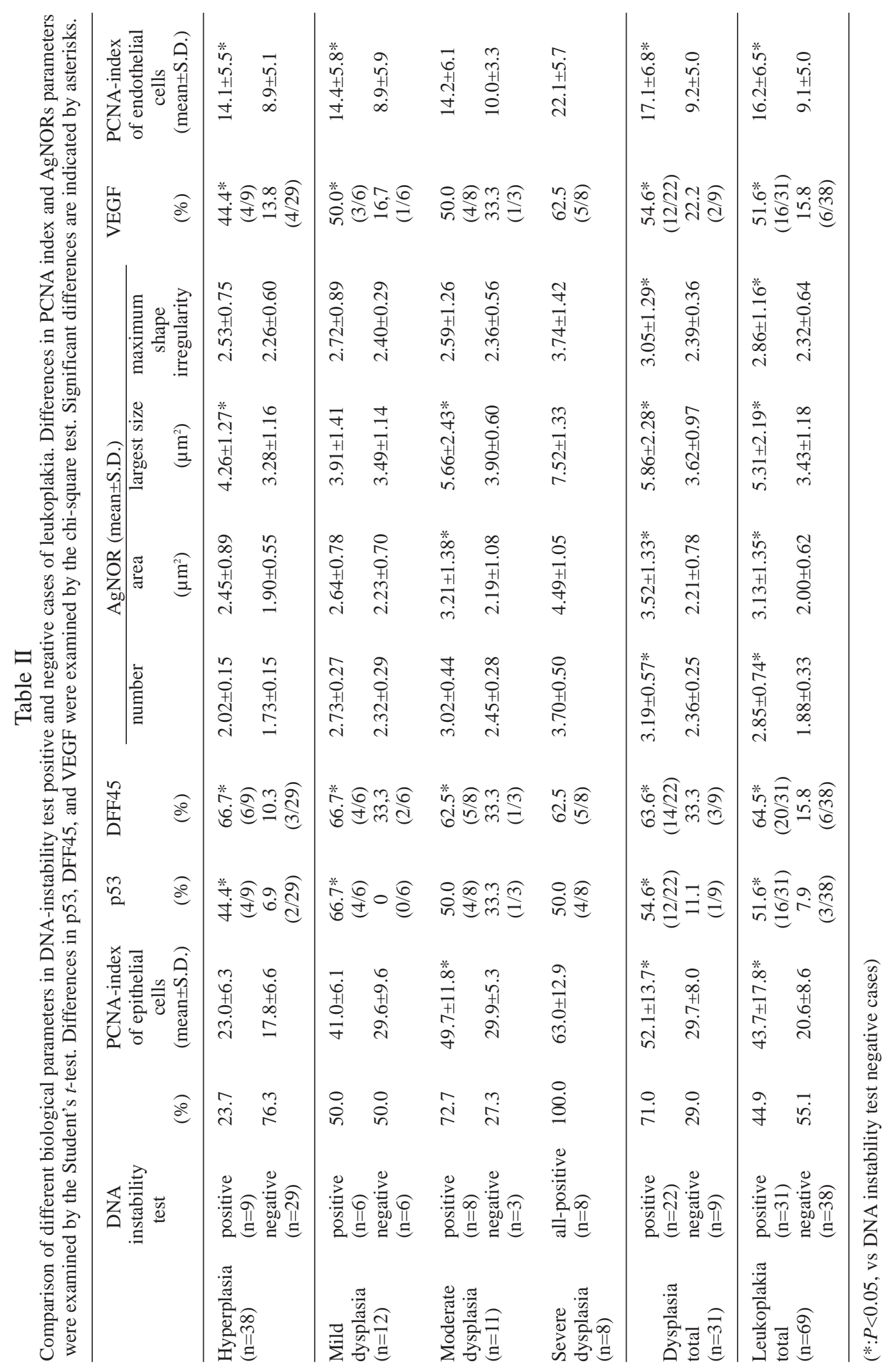



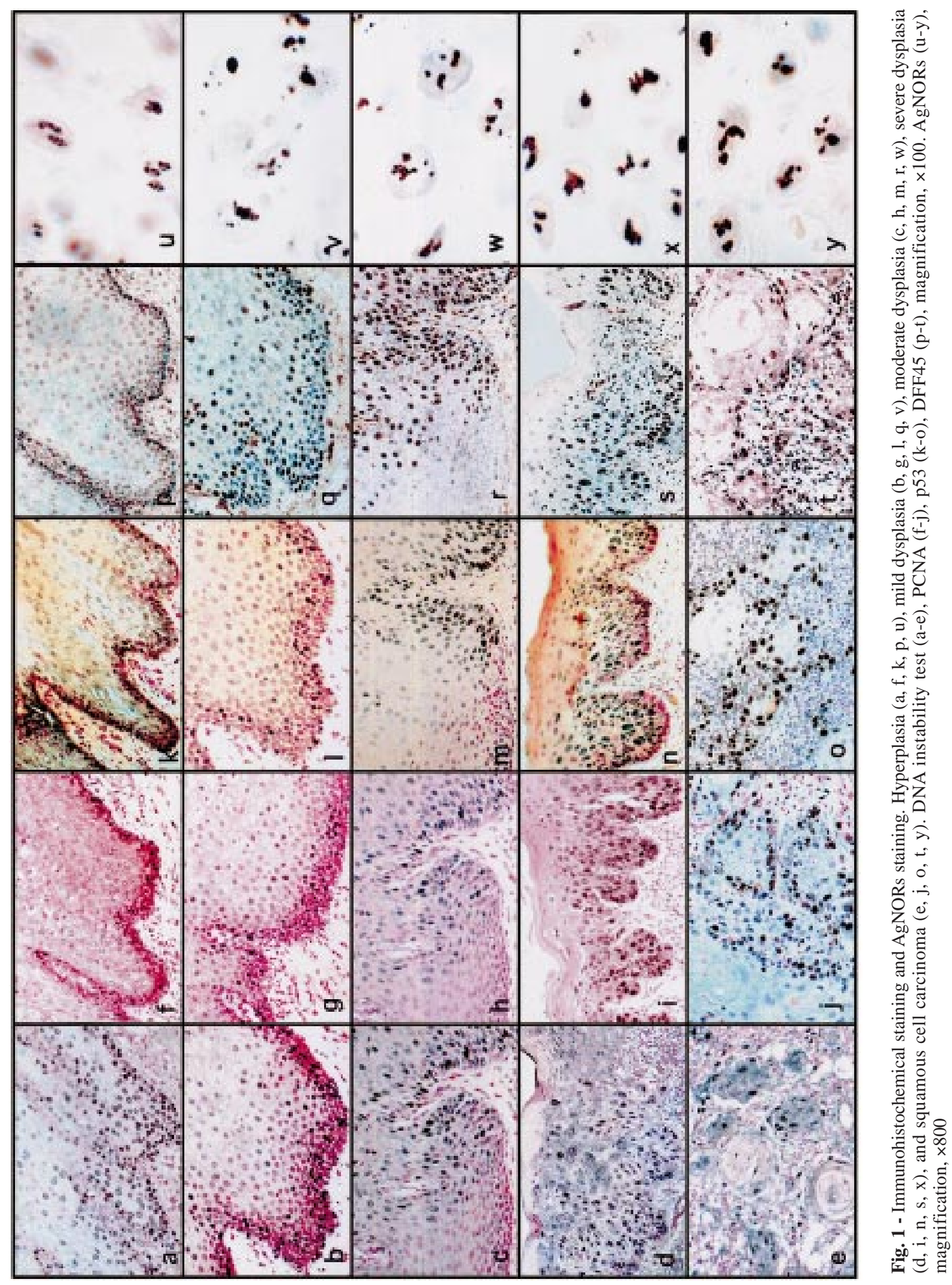
layer. In comparison, few p53-positive cells were present in the basal layer in hyperplasia and mild dysplasia, in more than one-third of he basal layer in moderate dysplasia, and in almost the entire thickness of the mucosa in severe dysplasia (Fig. 1 $\mathrm{k}, 1, \mathrm{~m}, \mathrm{n})$. In invasive cancer lesions, almost all cancer cells were p53-positive (Fig. 1o).

\section{DNA-fragmentation factor 45 immunohisto- chemistry}

Normal squamous epithelium was negative for DFF45. The proportions of DFF45-positive cases among hyperplasia, mild, moderate and severe dysplasia, total dysplastic lesions and SCC were $23.7,50.0,54.6,62.5,54.8$, and $75 \%$, respectively. The proportions of DFF45-positive cases with moderate and severe dysplasia, total dysplastic lesions and SCC were significantly different from that of hyperplasia, but those with each form of dysplasia were not different (Table I).

As shown in Table II, the proportion of DFF45positive cases with a positive DNA-instability test was significantly higher than those with a negative test. The distribution of DFF45-positive cells in all cases correlated well with that of DNA-instability test positive cells (Fig. 1 p,q,r,s,t).

\section{AgNORs parameters \\ AgNORs parameters were significantly higher in dysplasia and SCC lesions than in normal squa- mous epithelium (Table I). In hyperplasia, only the largest size parameter of AgNORs was significant- ly different from that of normal squamous epithe- lium. The maximum shape-irregularity parameter of dysplastic and SCC lesions was significantly higher than that of normal squamous epithelium, and the values of severe dysplasia and SCC were significantly higher than that of hyperplasia. AgNORs parameters of hyperplasia, mild, moder- ate and severe dysplasias, and total dysplastic lesions with a positive DNA-instability test were significantly higher than those of cases with a neg- ative DNA-instability test.}

\section{Triple immunostaining for VEGF, CD34 and PCNA}

VEGF-positive lesions contained many pale red cells stained with diffuse staining of the cytoplasm. CD34 staining appeared as a thin brownish staining of the cytoplasm of vascular endothelial cells. Both epithelial cells and vascular endothelial cells in the proliferative phases stained brown-black in tissues immunostained for PCNA (Fig. 2a,b, c, d).

Normal squamous epithelium was negative for VEGF. The proportions of cases positive for VEGF staining among hyperplasia, mild, moderate and severe dysplasia, total dysplastic lesions and SCC were 21.1, 33.3, 45.5, 62.5, 45.2, and $65.0 \%$, respectively. The proportions of severe dysplasia, total dysplastic lesions and SCC were significantly higher than that for hyperplasia (Table I). The proportions of vascular endothelial cells positive for PCNA in moderate dysplasia, total dysplastic lesions, and SCC were significantly higher than that for normal, and the values of severe dysplasia and SCC were significantly higher than that for hyperplasia. In all cases, except for moderate dysplasia, the values of the vascular PCNA index were significantly higher in cases with a positive DNA-instability test than in cases with a negative test (Table II).

\section{DISCUSSION}

The DNA-instability-test has been proposed by us as a specific marker of malignancy, irrespective of the epithelial or mesenchymal origin of tumors (Fukuda et al., 1986, 1993; Nitta et al., 1993; Otaki et al., 1994; Tsuzuki et al., 1994; Azuchi et al., 1998; Khaled et al., 2000). The method of differentially staining malignant cells either with acridine orange or anti-single-stranded DNA is based on the abundant production of denatured singlestanded DNA in cancerous cells after acid hydrolysis. Since the first report (Fukuda et al., 1986), we have applied the DNA-instability test in situ on more than 20,000 human malignancies: in our experience, this proved to be a reliable marker of malignant transformation, which should be applied in parallel with other markers that are already universally accepted.

Based on DNA-instability by acid hydrolysis, about a quarter of our cases of oral hyperplasia showed increased DNA-instability compared with invasive squamous cell carcinoma, suggesting that these lesions could be classified as malignant (Fig. 1a). Furthermore, the proportion of cases with a positive DNA-instability test increased progressively in mild, moderate and severe dysplastic 


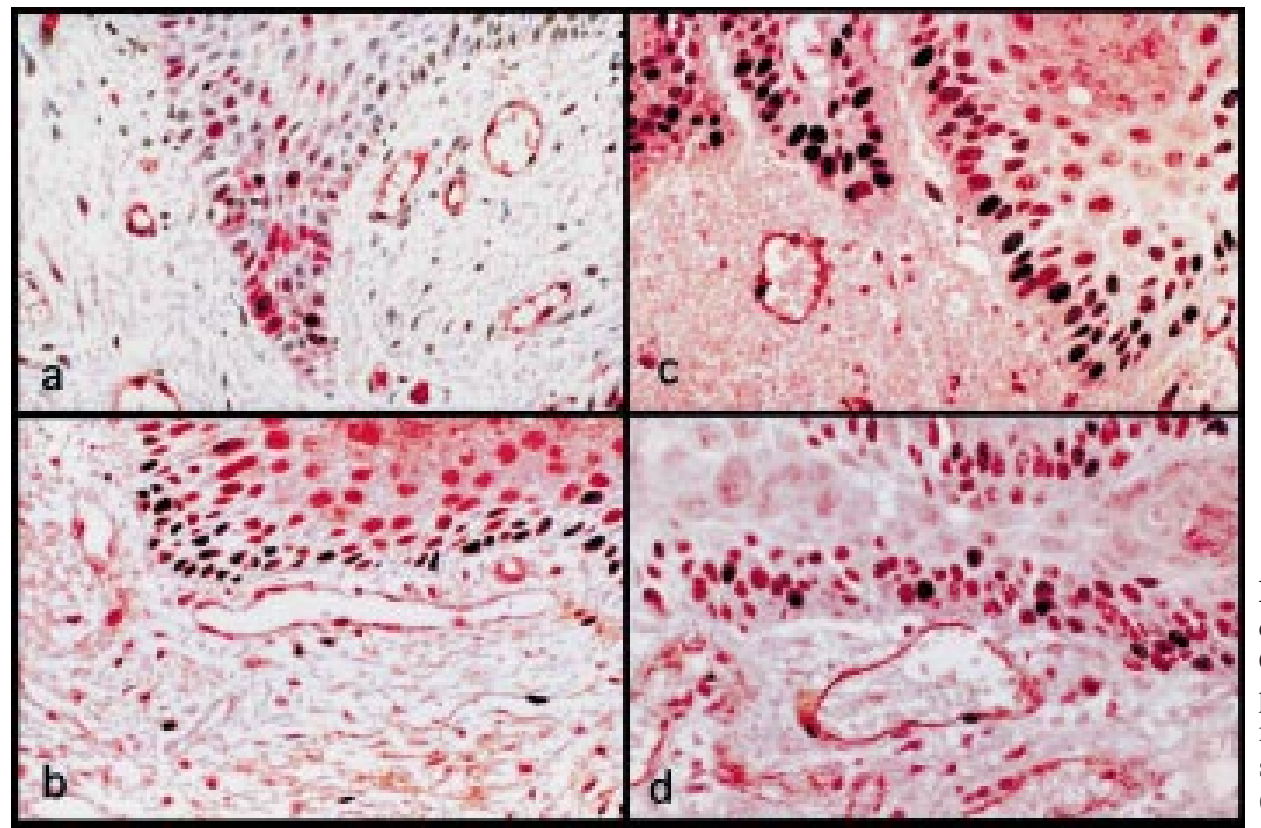

Fig. 2 - Immunohistochemical triple staining of VEGF, CD34 and PCNA in hyperplasia (a), mild dysplasia (b), moderate dysplasia (c), and squamous cell carcinoma (d). Magnification, $\times 200$.

lesions (50.0, 72.7, and 100\%, respectively) (Fig. 1 b,c,d), and all cancer cells of SCC lesions with a positive DNA-instability test were strongly positive (Fig. 1e). Moreover, positive immunostaining for PCNA, p53, DFF45, VEGF, and AgNORs parameters were noted in hyperplasia, and steadily increased along the course of progression from mild, moderate and severe dysplasia to invasive SCC (Tables I and II).

Our results showed that tissues with a positive DNA-instability test often exhibited abnormally high values for these biomarkers. However, they could not be distinguished from cases negative for these biomarkers, including the DNA-instability test, by morphological examination, because the degree of cellular atypia in these tissues was often not markedly pronounced, except for severe dysplasia and SCC.

Based on these findings, we herein propose the concept of "procancer" (as opposed to "pre-cancer") as being a unique stage during the course of carcinogenesis and cancer progression. We designate the term to cancer clones at the very early stages of malignant progression without distinguishable morphological atypia but with a positive DNA-instability test and positive staining for various biomarkers such as PCNA, p53, DFF45, VEGF and AgNORs parameters. We also define the abnormal positive staining of these biomarkers including the DNA-instability test as "functional atypia", compared to the ordinary morphological atypia. While morphological criteria seem to be the most reliable markers for the diagnosis of malignancy, it appears that a certain period is required before the degree of morphological atypia is manifested histopathologically to allow the diagnosis of malignancy, even after the formation of cancer clones. Increased DNA-instability as revealed by immunohistochemical staining with anti-single-stranded DNA antiserum after mild acid hydrolysis seems to reflect abundant qualitative alterations of DNA molecules within the cell nucleus. These DNA alterations allow the cell to manifest many abnormal biomarkers, which are suppressed in otherwise normal cells, and give rise to many different sub-populations through repeated mitosis.

PCNA, an auxiliary protein for DNA polymerase delta, plays an important role in the initiation of cell proliferation (Bravo et al., 1987; Jaskulsky et al., 1988). Prescreening of monoclonal antiPCNA antiserum used in the present study revealed that it reacted with all proliferating cells but not with mature cells and G0 cells. We defined, therefore, the percentage of PCNA-positive cells as the PCNA index, which seems to reflect the relative size of the proliferating cell fraction or growth fraction. Our results showed 
that the PCNA index steadily increased along the course of progression of malignancy, in agreement with other studies (Tsuji et al., 1992; Tsuzuki et al., 1994; Kobayashi et al., 1995), especially in tissues with a positive DNA-instability test (Fig. 1fj, Tables I and II).

Another important finding obtained by PCNA immunohistochemistry used in the present study is the loss of polarity of PCNA-positive cells, particularly in dysplasia and cancer lesions. In normal squamous epithelium, PCNA-positive cells were well localized in the basal layer, but the normal distribution was more or less disturbed in hyperplasia and mild dysplasia, especially in cases with a positive DNA-instability test, and remarkably disturbed in higher grade dysplasia and SCC. This finding indicates the presence of disturbed cell differentiation and proliferation in these lesions, and confirms the malignant characteristics of these tissues.

Wild type p53 protein plays a negative role in regulating cell proliferation by controlling entry of the cell into the $S$ phase and protecting against carcinogenesis (Finlay et al., 1988; Hollstein et al., 1991). Mutated p53 protein can be detected by immunohistochemistry (Bartek et al., 1990). The reported proportions of p53-positive lesions in hyperplastic, dysplastic and SCC cases are $21 \%$ (Girod et al., 1994), 36-55\% (Kaur et al., 1994; Girod et al., 1994), and 34-78\% (Nishioka et al., 1993; Kaur et al., 1994; Girod et al., 1994; Tuji et al., 1995), respectively. In this regard, Girod et al. (1994) demonstrated that the expression of mutant p53 protein intercorrelated with the degree of dysplasia, suggesting that it could be used as a good marker of malignant potential of oral leukoplakia (Tuji et al., 1995; Lee et al., 2000), although other investigators could not confirm these findings (Murti et al., 1998; Ries et al., 1998). In the present study, the proportion of p53-positive hyperplastic lesions was $15.8 \%$, but increased to $44.4 \%$ in hyperplastic lesions with a positive DNA-instability test and a further increase was noted in higher grade dysplasias and SCC. These results indicate that $\mathrm{p} 53$ mutation could be regarded as an early event during the sequential stages of oral carcinogenesis, which enhances further progression.

DNA fragmentation factor (DFF) plays an important role in the apoptotic pathway, which is activated by caspase 3 , and is involved in the formation of nuclear DNA fragments. DFF is a heterodimeric protein of 40 and $45 \mathrm{kDa}$ which is activated when DFF is cleaved by caspase-3. Of the two enzymatically cleaved fragments of DFF, the $40 \mathrm{kDa}$ fragment (DFF40) is the active component and is responsible for triggering chromatin condensation (Liu et al., 1997; Enari et al., 1998; Sabol et al., 1998; Samejima and Earnshaw, 1998; Sasaki et al., 1999). Increased proliferative activity, as revealed by PCNA immunohistochemistry and by the abnormal overexpression of apoptosis-related factors such as p53 and DFF45, seems to be an important feature of cancer cells and is associated with favourable survival of these cells. The abnormally high expression of DFF45 may be interpreted as induction of cancer cells to escape the apoptotic process. Induction of DFF45 protein should block the DNase activity of DFF40, thus allowing cancer cells to escape DNA fragmentation immediately before the final step of apoptosis.

Angiogenesis is an important process for tumour growth. Furthermore, VEGF is a specific mitogen for endothelial cells; it is overexpressed in oral high-grade dysplasia and SCC (Denhart et al., 1997) and, in fact, has been previously used as a prognostic factor of oral SCC (Maeda et al., 1998). In the present study, $21.1 \%$ of hyperplastic lesions were VEGF-positive. Furthermore, the proportion increased to $44.4 \%$ in the same cases with a positive DNA-instability test, indicating that VEGF overexpression may be an early event in oral carcinogenesis (Fig. 2, Tables I and II). Furthermore, PCNA indices of vascular endothelial cells in VEGF-positive cases were significantly high as revealed in triple immunostaining for VEGF, CD34, and PCNA (Fig. 2, Tables I and II). Another interesting finding in our study was the progressive increase in the proportion of VEGFpositive cases along the course of cancer progression, especially in cases with a positive DNAinstability test (Table II).

Nucleolar organizer regions (NORs) are chromosomal regions where genes for the major ribosomal RNA (18s,5-8s, and 28s) are located (Jordan, 1984). Several studies have shown that the size and number of AgNORs reflect the capability of cell proliferation (Reeves et al., 1984; Trere et al., 1991; Carmen et al., 1992) or the degree of malignancy (Arden et al., 1985; Egan and Crocker, 1992), although others have reported contradictory results (Griffiths et al., 1989). In lesions of the oral cavity, 
several groups have reported a positive correlation between AgNORs number and the degree of dysplasia and overt malignancy (Sano et al., 1991; Warnakulasuriya and Johnson, 1993; Kobayashi et al., 1995; Chattopadhyay et al., 1994). Tsuzuki et al. (1994) indicated that the AgNORs numbers and the values of maximum shape irregularities of AgNORs were significantly higher in oral dysplasia and SCC than in hyperplasia. In the present study, all AgNORs parameters including the maximum shape-irregularity, were significantly higher in dysplasia and SCC as compared with those of normal squamous epithelium, especially in cases with a positive DNA-instability test; and these values increased with progression to higher grade dysplasia and SCC.

The characteristic features described in "procancer" cells and cancer cells should favour proliferation of the descendants, enhance their survival by escaping the apoptotic process, and promote the availability of nutritional substances. These changes will enable these cells to produce more malignant clones with invasive and metastatic capabilities, although it is also possible that "procancer" cells may disappear by the escalating movement of squamous cells in the mucosa. Taken together, it is important to detect "procancer" clones at the early stages of carcinogenesis using effective biomarkers, and identify "functional atypia" by the DNA instability test in addition to the ordinary diagnostic criteria of morphological atypia, to improve prognosis in patients with oral leukoplakia.

\section{REFERENCES}

Arden K.C., Pathak S., Frankel L.S., and Zander A.: AgNOR staining in human chromosomes: differential staining in normal and leukemic bone- marrow samples. Int. J. Cancer 36, 647-649, 1985.

Axéll T, Pindborg J.J., Smith C.J., Waal van der I., and International Collaborative Group on Oral White Lesions: Oral white lesions with special reference to precancerous and tobacco-related lesions: conclusions of an international symposium held in Uppsala, Sweden, May 18-21, 1994. J Oral Pathol Med. 25, 49-54, 1996.

Azuchi M., Baba H., Imura S., Noriki S., Imamura Y., and Fukuda M : Demonstration of biological aggressiveness of bone giant cell tumor by the comparative study of immunohistochemical detection of DNA- instability and cortical destruction by CT. Acta. Histochem. Cytochem. 31, 401-410, 1998.
Bartek J., Iggo R., Gannon J., and Lane D.B.: Genetic and immunohistochemical analysis of mutant p53 in human breast cancer cell lines. Oncogene 5, 893-899, 1990.

Bouquot J.E., and Gnepp D.R.: Laryngeal precancer : a review of the literature, commentary, and comparison with oral leukoplakia. Head and Neck 13, 488-497, 1991.

Bravo R., Frank R., Blundell P.A., and MacDonald B.H.: Cyclin/PCNA is the auxiliary protein of DNA polymerase delta. Nature 309, 515-520, 1987.

Burkhardt A.: Advanced methods in the evaluation of premalignant lesions and carcinomas of the oral mucosa. J. Oral Pathol.14, 751- 778, 1985.

Carmen C.W., Christopher D.M., Paul L.N., John R.G., Julia C.B., and David A.L.: A comparison of proliferating cell nuclear antigen (PCNA) immunostaining, nucleolar organizer region (AgNOR) staining, and histological grading in gastrointestinal stromal tumors. J. Pathol.166, 147-152, 1992.

Chattopadhyay A., Chawda, J.G., and Doshi, J.J.: Silverbinding nucleolar organizing regions: a study of oral leukoplakia and squamous cell carcinoma. Int. J. Oral Maxillofac. Surg. 23, 374-377, 1994.

Denhart B.C., Guidi, A.J., Tongazzi K., Dvorac H.F., and Brown, L.F.: Vascular permeability factor/vascular endothelial growth factor and its receptors in oral and laryngeal squamous cell carcinoma and dysplasia. Lab. Invest 77, 659-664, 1997.

Egan M.J., and Crocker J.: Nucleolar organizer regions in cutaneous tumors. J. Pathol. 154, 247-253, 1988.

Einhorn J., and Wersäll J.: Incidence of oral carcinoma in patients with leukoplakia of oral mucosa. Cancer 20, 2184 2193, 1967.

Enari M., Sakahira H., Yokoyama H., Okawa K., Iwamatsu A., and Nagata S.: A caspase-activated DNase that degrades DNA during apoptosis, and its inhibitor ICAD. Nature 391, 43-45, 1998.

Finlay C.A., Hinds P.W., Tan T.H., Eliyahu D., Oren M., and Levine A.J.: Activating mutations for transformation by $\mathrm{p} 53$ produce a gene product that forms an hsc 70-p53 complex with an altered half life. Mol. Cell Biol. 8, 531-539, 1988.

Fukuda M., Miyoshi N., Hattori T., Sugihara H., Hosokawa Y., and Nakanishi K.: Different instability of nuclear DNA at acid hydrolysis in cancerous and non-cancerous cells as revealed by fluorescent staining with acridine orange. Histochemistry. 84, 556-560, 1986.

Fukuda M., Noriki S., Imamura Y., Miyoshi N., Kimura S., Koizumi K., Suzuki K., Sakurai H., and Sakaguchi R.: Differential immunohistochemical staining of cancerous cells with anti-single-stranded DNA antiserum in ordinary pathological paraffin section after DNA-denaturation by acid hydrolysis. Eur. J. Histochem. 37, 309-319, 1993.

Garzino D. P., Carrozzo M., Trusolino L., Savoia P., Gandolfo S., and Marchisio P.C.: Altered expression of alpha 6 integrin subunit in oral squamous cell carcinoma and oral potentially malignant lesions. Oral Oncol. 34, 204-210, 1998. 
Girod S.C., Krämer C., Knüfermann R., and Krueger G.R.F.: P53 expression in the carcinogenesis in the oral mucosa. $\mathrm{J}$. Cell Biochem. 56, 444-448, 1994.

Griffiths A.P., Butler C.W., Roverts P., Dixon M.F., and Quirke P.: Silver - stained structures (AgNORs), their dependence on tissue fixation and absence of prognostic relevance in rectal adenocarcinoma. J. Pathol. 159, 121-127, 1989.

Hakkinen L., Kainulainen T., Salo T., Grenman R., and Lariava $H .:$ Expression of integrin alpha9 subunit and tenascin in oral leukoplakia, lichen planus, and squamous cell carcinoma. Oral Dis. 5, 210-217, 1999.

Hansen, L.S., Olson, J.A., and Silverman, S.: Proliferative verrucous leukoplakia. Oral Surgery, Oral Medicine, Ora Pathol. 60, 285-298, 1985.

Hollstein M., Sidransky D., Vogelstein, B., and Haris, C.C.: p53 mutation in human cancers. Science 25, 49-53, 1991.

Ibrahim S.O., Warnakulasuriya K.A.A.S., Idris A.M., Hirsch J.M., Johnson N.W. and Johanessen A.C.: Expression of keratin 13, 14 and 19 in oral hyperplastic and dysplastic lesions from Sudanese and Swedish snuff-dippers: Association with human papillomavirus infection. Anticancer Res. 18, 635-646, 1998.

Jaskulsky D., deRiel J.K., Mercer W.E., Calbretta B., and Baserga R.: Inhibition of cellular proliferation by antisense oligodeoxynucleotides to PCNA/cyclin. Science 240, 1544 1546, 1988.

Jordan E.G.: Nucleolar nomenclature. J. Cell Sci. 67, 217-220, 1984.

Karabulut A., Reibel, J., Therkildsen, M.H., Praetrius, F. Nielsen, H.W., and Dabelsteen, E.: Observer variability in the histologic assessment of oral premalignant lesions. J. Oral Pathol. Med. 24, 198-200, 1995.

Kaur J, Srivastava A., and Ralhan R.: Over expression of p53 protein in betel and tobacco related human oral dysplasia and squamous cell carcinoma in India. Int. J. Cancer. 58, 340-345, 1994.

Khaled A., Imamura Y., Noriki S., and Fukuda M.: Early progression stage of malignancy of uterine cervical dysplasia as revealed by immunohistochemical demonstration of increased DNA instability. Eur. J. Histochem. 44, 143-156, 2000.

Kobayashi I., Matsuo K., Ozeki S., Ohishi M., Ishibashi Y. and Sakai H.: The proliferative activity in oral epithelial dysplasia analyzed by proliferating cell nuclear antigen immunostaining and argyrophilic nucleolar organizer region staining. Human Pathol. 26, 907-913, 1995.

Kramer I.R.H., Lucas R.B., Pindborg J.J., Sobin L.H., WHO Collaborating Centre for Oral Precancerous Lesions: Definition of leukoplakia and related lesions: An aid to studies on oral precancer. Oral Surg. Oral Med. Oral Pathol. 46, 518-539, 1978.

Lee J.J., Hong W.K., Hittelman W.N., Mao L., Lotan R., Shin D.M., Benner S.E., Xu X.C., Lee J.S., Papadimitrakopoulou V.M., Geyer C., Perez C., Martin J.W., El-Nagger A.K., and Lippman S.M.: Predicting cancer development in oral leukoplakia: Ten years of translational research. Clin. Cancer Res. 6, 1702-1710, 2000.
Liu X., Zou H., Slaughter C., and Wang X.: DFF, a heterodimeric protein that functions downstream of caspase-3 to trigger DNA fragmentation during apoptosis. Cell 89, 175$184,1997$.

Maeda T., Matsumura S., Hiranuma H., Jikko A., Furukawa S., Ishida T., and Fuchihata H.: Expression of vascular endothelial growth factor in human oral squamous cell carcinoma : its association with tumour progression and p53 gene status. Clin. Pathol. 51, 771-775, 1998.

Muraki Y., Yoshioka C., Fukuda J., Haneji T., and Kobayashi N.: Immunohistochemical detection of Fas antigen in oral epithelia. J. Oral Pathol. Med. 26, 57-62, 1997.

Murti P.R., Warnakulasuriya K.A.A.S., Johnson N.W., Bhonsle R.B., Gupta P.C., Daftary D.K., and Mehta F.S.: p53 expression in oral precancer as a marker for malignant potential. Oral Pathol. Med. 27, 191-196, 1998.

Nishioka H, Hiasa Y., Hayashi I., Kitahori Y., Konishi N., and Sugimura M.: Immunohistochemical detection of p53 oncoprotein in human oral squamous cell carcinomas and leukoplakias: comparison with proliferating cell nuclear antigen staining and correlation with clinicopathological findings. Oncology 50, 426-429, 1993.

Nitta Y., Suzuki K., Kohli Y., Fujiki N., Imamura Y., Noriki S., and Fukuda M.: Early progression stage of malignancy of human colon border-line adenoma as revealed by immunohistochemical demonstration of DNA instability. Eur. J. Histochem. 37, 207-218, 1993

Otaki T., Kohli Y., Fujiki N., Imamura Y., and Fukuda M.: Early progression stage of malignancy as revealed by immunohistochemical demonstration of DNA instability; I, human gastric adenomas. Eur. J. Histochem. 38, 281-290, 1994

Pindborg J.J., Reibel J., and Holmstrup P.: Subjectivity in evaluating oral epithelial dysplasia, carcinoma in situ and initial carcinoma. J. Oral Pathol. 14, 698-708, 1985.

Ramaesh T., Mendis B.R.R.N., Ratnatunga N., and Thattil RO.: Cytomorphometric analysis of squamous obtained from normal oral mucosa and lesions of oral leukoplakia and squamous cell carcinoma. J. Oral Pathol. Med. 27, 83-86, 1998.

Ravi D., Narlinakumari K.R., Rajaram R.S., Nair K.N., and Pillai M.R. : Expression of programmed cell death regulatory p53 and bcl-2 proteins in oral lesions. Cancer Lett. 105, 139146,1996

Reeves B.R., Casay G., Honeycombe J.R., and Smith S.: Correlation of differentiation state and silver staining of nucleolar organizers in the promyelocytic leukemia cell line HL-60. Cancer Genet. Cytogenet. 13, 159-166, 1984

Ries J.C., Schreiner D., Steininger H., and Girod S.C.: P53 Mutation and detection of p53 protein expression in oral leukoplakia and oral squamous cell carcinoma. Anticancer Res. 18, 2031-2036, 1998

Sabol S.L., Li R., Lee T.Y., and Khalex R.A.: Inhibition of apoptosis-associated DNA fragmentation activity in nonapoptotic cells: The roll of DNA fragmentation factor-45 (DFF45/ICAD). Biochem. Biophys. Res. Commun. 253, 151-158, 1998. 
Samejima K. and Earnshaw W.C.: ICAD/DFF regulator of apoptotic nuclease is nuclear. Exper. Cell Res. 243, 453-459, 1998.

Sano K., Takahashi H., Fujita S., Inokuchi T., Pe M.B., Okabe H., and Tsuda N.: Prognostic implication of silver-binding nucleolar organizer regions (AgNORs) in oral squamous cell carcinoma. J. Oral Pathol. Med. 20, 53-56, 1991

Sasaki H., Suzuki T., Funaki N., Hoshi T., Iwabuchi M., Ohi R., and Sasano H.: Immunohistochemistry of DNA fragmentation factor in human stomach and colon: its correlation to apoptosis. Anticancer Res. 19, 5277-5282, 1999.

Schepman K.P., Meij V.D.E.H., Smeele L.E., and Wall V.D.I.: Malignant transformation of leukoplakia: a follow-up study of a hospital-based population of 166 patients with oral leukoplakia from The Netherlands. Oral Oncol. 34, 270-275, 1998.

Silverman S., Gorsky M., and Lozada F.: Oral leukoplakia and malignant transformation. A follow-up study of 257 patients. Cancer 53, 563-568, 1984.

Silverman S., and Gorsky M.: Proliferative verrucous leukoplakia. A follow-up study of 54 cases. Oral Surg. Oral Med. Oral Pathol. Oral Radiol. Endod. 84, 154-157, 1997.

Thomson P.J., Potten, C.S., and Appleton, D.R.: Characterization of epithelial cell activity in patients with oral cancer. Br. J. Oral. Maxillofac. Surg. 37, 384-390, 1999.
Trere D., Farabegoli F., Cancellieri A., Ceccarelli C., Eusebi V., and Derenzini M.: AgNOR area in interphase nuclei of human tumours correlates with the proliferative activity evaluated by bromodeoxyuridine labeling and Ki-67 immunostaining. J. Pathol. 165, 53-59, 1991.

Tsuji T., Sasaki K., Kimura Y., Yamada K., Mori M., and Shinozaki F.: Measurement of proliferating cell nuclear antigen (PCNA) and its clinical application in oral cancers. Int. J. Oral Maxillofac. Surg. 21, 369-372, 1992.

Tuji T., Mimura Y., Wen S., Li X., Kanekawa A., Sasaki K., and Shinozaki F.: The significance of PCNA and p53 protein in some oral tumors. Int. J. Oral Maxillofac. Surg. 24, 221$225,1995$.

Tsuzuki H., Saito H., Imamura Y., and Fukuda M.: Early progression stage of malignancy as revealed by immunohistochemical demonstration of DNA instability; otorhinolaryngeal borderline neoplastic lesions. Eur. J. Histochem. 38, 291-302, 1994.

Vaidya M.M., Sawant S.S., Borges A.M., Ogale S.B. and Bhisey A.N.: Cytokeratin expression in precancerous lesions of the human oral cavity. Oral Oncol. 34, 261-264, 1998.

Warnakulasuriya K.A.A.S., and Johnson N.W.: Nucleolar organizer region (NOR) distribution as a diagnostic marker in oral keratosis, dysplasia and squamous cell carcinoma. J. Oral Pathol. Med. 22, 77-81, 1993. 